\title{
Abnormal expression and processing of uromodulin in Fabry disease reflects tubular cell storage alteration and is reversible by enzyme replacement therapy
}

\author{
P. Vylet'al • H. Hůlková • M. Živná • L. Berná • \\ P. Novák • M. Elleder • S. Kmoch
}

Received: 20 February 2008/Submitted in revised form: 21 April 2008/Accepted: 23 April 2008 /Published online: 27 July 2008

(C) SSIEM and Springer 2008

\begin{abstract}
Summary Uromodulin (UMOD) malfunction has been found in a range of autosomal dominant tubulointerstitial nephropathies associated with hyperuricaemia, gouty arthritis, medullary cysts and renal failure-labelled as familial juvenile hyperuricaemic nephropathy, medullary cystic disease type 2 and glomerulocystic kidney disease. To gain knowledge of the spectrum of UMOD changes in various genetic diseases with renal involvement we examined urinary UMOD excretion and found significant quantitative and qualitative changes in 15 male patients at various clinical stages of Fabry disease. In untreated patients, the changes ranged from normal to a marked decrease, or even absence of urinary UMOD. This was accom-
\end{abstract}

\section{Communicating editor: Ed Wraith}

Competing interests: None declared

References to electronic databases: Fabry disease: OMIM 301500. $\alpha$-Galactosidase A: EC 3.2.1.22. Uromodulin, OMIM 191845.

P. Vylet'al · M. Živná $\cdot$ M. Elleder $\cdot$ S. Kmoch

Center for Applied Genomics and Institute for Inherited

Metabolic Disorders, Charles University 1st Faculty

of Medicine, Prague, Czech Republic

H. Hůlková • L. Berná

Institute for Inherited Metabolic Disorders, Charles

University 1st Faculty of Medicine, Prague, Czech Republic

P. Novák

Laboratory of Molecular Structure Characterization,

Institute of Microbiology, Academy of Sciences

of the Czech Republic, Prague, Czech Republic

S. Kmoch $(\square)$

Center for Applied Genomics and Institute for Inherited

Metabolic Disorders, Ke Karlovu 2,

12800 Prague 2, Czech Republic

e-mail: skmoch@lf1.cuni.cz panied frequently by the presence of aberrantly processed UMOD lacking the C-terminal part following the K432 residue. The abnormal patterns normalized in all patients on enzyme replacement therapy and in some patients on substrate reduction therapy. Immunohistochemical analysis of the affected kidney revealed abnormal UMOD localization in the thick ascending limb of Henle's loop and the distal convoluted tubule, with UMOD expression inversely proportional to the degree of storage. Our observations warrant evaluation of tubular functions in Fabry disease and suggest UMOD as a potential biochemical marker of therapeutic response of the kidney to therapy. Extended comparative studies of UMOD expression in kidney specimens obtained during individual types of therapies are therefore of great interest.

\begin{tabular}{|c|c|}
\hline \multicolumn{2}{|l|}{ Abbreviations } \\
\hline DCT & distal convoluted tubule \\
\hline ERT & enzyme replacement therapy \\
\hline $\mathrm{Gb}_{3}$ & globotriaosylceramide \\
\hline GLA & $\alpha$-galactosidase $\mathrm{A}$ \\
\hline MALDI-TOF & $\begin{array}{l}\text { matrix assisted lased desorption/ } \\
\text { ionization-time of flight }\end{array}$ \\
\hline SRT & substrate reduction therapy \\
\hline TALH & thick ascending limb of Henle's loop \\
\hline UAKD & uromodulin-associated kidney disease \\
\hline UMOD & uromodulin \\
\hline
\end{tabular}

\section{Introduction}

Uromodulin (UMOD; OMIM 191845) or Tamm-Horsfall protein (THP) is a protein selectively expressed in the 
thick ascending limb of Henle's loop (TALH), the macula densa segment and the distal convoluted tubule (DCT) (Hoyer and Seiler 1979; Peach et al 1988; Schenk et al 1971; Sikri et al 1981). Normally the synthesized protein is glycosylated, glypiated, secreted and glycosylphosphatidylinositol-anchored in the apical membrane of the polarized renal tubular epithelial cells (Kreft et al 2002; Rindler et al 1990; Serafini-Cessi et al 1993), from where it is continuously released by a specific but not yet identified protease (Cavallone et al 2001; Fukuoka and Kobayashi 2001). UMOD is excreted in the urine at the rate of $50-100 \mathrm{mg} /$ day, which makes it one of the most abundant urinary proteins (Kumar and Muchmore 1990). UMOD precipitates in the urine and is the main constituent of urinary casts (Cohen 1981; Fairley et al 1983; Wenk et al 1981).

Mutations in the uromodulin gene (HGNC UMOD) were found in a subset of patients suffering from a range of autosomal dominant tubulointerstitial nephropathies associated with hyperuricaemia, gouty arthritis, medullary cysts and renal failure-labelled as familial juvenile hyperuricaemic nephropathy (FJHN, OMIM 162000), medullary cystic disease type 2 (MCKD2, OMIM 603860) (Hart et al 2002) and glomerulocystic kidney disease (GCKD, OMIM 609886) (Rampoldi et al 2003). In these patients $U M O D$ mutations led to intracellular UMOD accumulation, absence of the protein on the plasma membrane and decreased urinary excretion (Bernascone et al 2006; Bleyer et al 2004; Dahan et al 2003; Hodanova et al 2005; Rampoldi et al 2003; Vylet'al et al 2006). Changes in UMOD expression, cellular localization and urinary excretion were found also in FJHN/MCKD patients with no $U M O D$ mutation and this led to introduction of the term 'uromodulin-associated kidney diseases' (UAKD) (Hart et al 2002; Hodanova et al 2005; Vylet'al et al 2006).

As it is unclear as to what extent the changes in UMOD expression, cellular localization and urinary excretion are specific to FJHN/MCKD/UAKD, we are examining these parameters in other genetic diseases with severely compromised renal functions.

Fabry disease (OMIM 301500) is an X-linked, gonosomal recessive disorder caused by deficiency of $\alpha$-galactosidase A (GLA; EC 3.2.1.22.). The enzyme defect leads to massive accumulation and storage of non-degraded substrate globotriaosylceramide $\left(\mathrm{Gb}_{3}\right)$ in lysosomes of various cell types. Hemizygous male patients manifest a wide range of symptoms, including characteristic skin lesions, chronic progressive painful small-fibre neuropathy, corneal opacities, renal failure, heart disease and stroke due to systemic vasculopathy. If untreated, the disease is lethal, renal failure being the usual cause of death (Desnick et al 1989; Masson et al 2004).

The Fabry storage nephropathy has attracted biomedical interest mainly owing to deterioration of glomerular function, starting with increased protein permeability, followed by progressive hyalinization and loss of the filtration capacity. This process as such has been studied intensively at clinical and pathological levels (Burkholder et al 1980; Glass et al 2004; McNary and Lowenstein 1965; Morel-Maroger et al 1966; Pabico et al 1973) among others with the intention of defining 'the point of no return' for enzyme replacement therapy (ERT) (Breunig and Wanner 2003; De Schoenmakere et al 2003; del Toro et al 2004). Renal tubular dysfunction in Fabry disease was described earlier by Pabico and colleagues (Pabico et al 1973) but attracted little attention. However, tubular dysfunction has been described as being prominent during the early clinical course (Parchoux et al 1978; Wornell et al 2006).

In this study of 15 male Fabry disease patients in various clinical stages of the disease, we examined UMOD urinary excretion and protein proteolytic processing and found significant quantitative and qualitative abnormalities. Interestingly, these changes normalized in every single patient treated by ERT (Fabrazyme or Replagal) but not as successfully in the patients on substrate reduction therapy (SRT) using the ceramide glucosyltransferase inhibitor Zavesca.

To explain the observed abnormalities we studied UMOD cellular localization in different parts of the nephron and collecting duct in kidney tissue from three untreated patients. These studies revealed abnormal UMOD localization in TALH and collecting tubules, with UMOD expression in TALH epithelia being inversely proportional to the degree of storage. In contrast to previous studies, which have largely looked at functional changes, our study shows for the first time a biochemically defined alteration of tubular cell biology reflecting the process of storage in defined parts of the nephron. Although the mechanisms by which the enzyme defect and/or storage process lead to abnormal UMOD expression, processing and urinary excretion remain unknown. Our observations warrant further evaluation of tubular functions in Fabry disease patients and suggest UMOD as a potential biochemical marker of response of the kidney to therapy. 


\section{Materials and methods}

\section{Patients}

For the analyses, urine samples were collected from 15 male patients with Fabry disease with a range of ages, severity of symptoms and types of treatment. The diagnosis of Fabry disease in the selected patients was made following the finding of reduced GLA activity in leukocytes and the presence of a pathogenic mutation in the GLA gene (HGNC GLA). Basic clinical, biochemical and molecular data as well as the treatment regimens for all 15 patients are summarized in Table 1. All the patients were from the Czech Republic and were diagnosed and studied in our Institute (Dobrovolny et al 2005).

\section{SDS-PAGE and western blot}

Urine samples stored at $-80^{\circ} \mathrm{C}$ were thawed and $15 \mu \mathrm{l}$ of sample was denatured using standard SDSPAGE loading buffer. Proteins were separated on $10 \%$ SDS-polyacrylamide gel and UMOD was detected using western blot analysis as described previously (Hodanova et al 2005).

\section{Deglycosylation experiments}

Deglycosylation experiments were performed on $15 \mu \mathrm{l}$ of total urine using the GlycoPro enzymatic deglycosylation kit (ProZyme Inc., San Leandro, CA, USA) according to the manufacturer's instructions. Deglycosylated protein products were directly analysed on $10 \%$ SDS-polyacrylamide gel and UMOD was detected by western blot as described above.

\section{Mass spectrometry}

To characterize UMOD variants, total protein from $500 \mu \mathrm{l}$ of each patient's urine was recovered on Microcon YM-50 columns (Milipore, Bedford, MA, USA) and separated on $10 \%$ SDS-polyacrylamide gel. Coomassie blue R 250 stained protein bands were extracted from the gel and digested with trypsin (Promega, Madison, WI, USA, $5 \mathrm{ng} / \mu \mathrm{l})$. The resulting peptides were extracted and subjected to mass-spectrometric analysis.

Mass spectra were measured using the following. (a) A matrix-assisted laser desorption/ionization reflectron time-of-flight MALDI-TOF mass spectrometer BIFLEX II (Bruker-Franzen, Bremen, Germany) equipped with a nitrogen laser (337 nm) and gridless delayed extraction ion source. Spectra were calibrated externally using the monoisotopic $[\mathrm{M}+\mathrm{H}]^{+}$ion of peptide standard somatostatin (Sigma-Aldrich, Prague, Czech Republic). A saturated solution of $\alpha$-cyano-4hydroxycinnamic acid in 50\% CAN-0.2\% TFA was used as a MALDI matrix. (b) A LCQ ${ }^{\text {DECA }}$ ion trap mass spectrometer (ThermoQuest, San Jose, CA, USA) equipped with a nanoelectrospray ion source (ESI LC-MS/MS). Magic-C18 column, $0.2 \times 150 \mathrm{~mm}$, $200 \AA$ Å, $5 \mu \mathrm{m}$ (Michrom Bioresources, Auburn, CA,

Table 1 Clinical, biochemical and molecular information on patients

\begin{tabular}{|c|c|c|c|c|c|c|}
\hline Patient & DOB & GLA mutation & GLA activity ${ }^{\mathrm{a}}$ & Mainz score & Renal index & Treatment ${ }^{\mathrm{b}}$ \\
\hline P1 & 1945 & c.801ins36 & 2.4 & 34 & 0 & $\mathrm{Z}(12), \mathrm{F}(12)$ \\
\hline $\mathrm{P} 2$ & 1949 & delEx2 & 2.6 & 56 & 18 & $\mathrm{Z}(12), \mathrm{F}(45)$ \\
\hline P3 & 1952 & R301X & 2.9 & 54 & 18 & $\mathrm{Z}(12), \mathrm{F}$ \\
\hline P4 & 1957 & L294X & 1.0 & 54 & 18 & $\mathrm{Z}, \mathrm{T}, \mathrm{F}(5)$ \\
\hline P5 & 1960 & c.801ins 36 & 1.7 & 41 & 4 & $\mathrm{Z}, \mathrm{F}(14)$ \\
\hline P6 & 1968 & c.674del59 & 0.7 & 41 & 18 & $\mathrm{R}(2)$ \\
\hline P7 & 1972 & N215S & 7.2 & - & 0 & $\mathrm{~N}$ \\
\hline P8 & 1978 & $\mathrm{D} 155 \mathrm{H}$ & 1.7 & 41 & 18 & $\mathrm{Z}, \mathrm{F}$ \\
\hline P9 & 1979 & N215S & 5.2 & 5 & 0 & $\mathrm{~N}$ \\
\hline $\mathrm{P} 10$ & 1985 & G360S & 1.9 & - & 0 & $\mathrm{~N}$ \\
\hline P11 & 1956 & Q280K & 1.2 & 35 & 4 & $\mathrm{Z}(12), \mathrm{F}(45)$ \\
\hline $\mathrm{P} 12$ & 1978 & R342Q & 3.4 & 32 & 8 & $\mathrm{R}(3)$ \\
\hline P13 & 1972 & R342Q & 0.3 & 41 & 4 & $\mathrm{R}(3)$ \\
\hline P14 & 1966 & R342Q & 1.8 & 28 & 0 & $\mathrm{Z}(12)$ \\
\hline P15 & 1948 & R301X & 1.9 & 44 & 4 & $\mathrm{Z}(12), \mathrm{F}(13)$ \\
\hline
\end{tabular}

${ }^{a}$ GLA activity in leukocytes measured at $37^{\circ} \mathrm{C}$; average of 100 controls $53.8 \pm 11,5$ and range $32-89 \mathrm{nmol} / \mathrm{mg}$ per hour.

${ }^{\mathrm{b}}$ Z, Zavesca; F, Fabrazyme; R, Replagal; N, none; T, transplantation; duration of the treatment is given in months in parentheses. 
USA) and $\mathrm{MeCN}$-acetic acid gradient was used for peptide separation. Positive-ion full scan and CID mass spectra over $\mathrm{m} / \mathrm{z}$ range $350-1600$ were acquired and interpreted by SEQUEST software against the human NCBI database.

\section{Immunohistochemistry studies}

Archived formalin-fixed paraffin-embedded kidney samples originated from two autopsied adult males and one female with Fabry disease, who died at 47, 44 and 63 years respectively. The storage was detected in fixed frozen section, using the periodic acid-Schiff (PAS) method (checked by lipid extraction) and by birefringence. In paraffin sections, it was indicated by the typical foamy appearance of the storage cells.

Immunodetection of UMOD and of the apical cell membrane marker MUC1 was done in paraffin sections as previously described (Vylet'al et al 2006). For designation of individual parts of the kidney tubular system the nomenclatures of Clapp and Croker was used (Clapp and Croker 1997), i.e. nephron (consisting of proximal tubule, Henle loop and distal convoluted tubule) and the collecting tubule.

\section{Results}

\section{Analysis of urinary UMOD}

For an overview on the nature and range of eventual changes in urinary UMOD excretion we analysed urine samples from 15 Fabry patients with a range of age, severity of symptoms and treatment regimens (Table 1).

Initially, we analysed UMOD excretion patterns in urine samples collected before any treatment was started (Fig. 1). The analysis showed that in some of the patients UMOD excretion was strongly decreased $(\mathrm{P} 3, \mathrm{P} 8)$ or reduced $(\mathrm{P} 5)$, along with abnormal forms

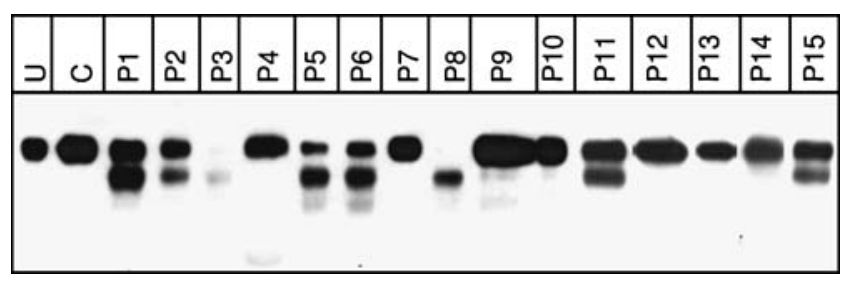

Fig. 1 Qualitative analysis (western blot) of urinary UMOD in patients with Fabry disease before the therapy. U: UMOD standard isolated from control urine. C: control urine. P1-P15: patient designation as provided in Table 1 of anti-UMOD immunoreactive protein $(\mathrm{P} 1, \mathrm{P} 2, \mathrm{P} 3$, $\mathrm{P} 5, \mathrm{P} 6, \mathrm{P} 8, \mathrm{P} 11, \mathrm{P} 15)$. In other patients, UMOD excretion seemed to be normal (P4, P7, P9, P10, P12, $\mathrm{P} 13, \mathrm{P} 14)$. As indicated in Table $1, \mathrm{P} 4$ was tested after kidney transplantation and patients $\mathrm{P} 7, \mathrm{P} 9$ and $\mathrm{P} 10$ showed a mild clinical phenotype.

To identify the nature of the anti-UMOD immunoreactive protein found in urines of some Fabry disease patients, we first deglycosylated urine from patient P1 with $N$-glycanase (PGNase $\mathrm{F}$ ) and subjected the resulting UMOD profile to western blot analysis (Fig. 2a). The analysis suggested that the abnormal anti-UMOD immunoreactive protein did not represent a different UMOD glycoform but rather a UMOD protein differing in its peptide moiety. We therefore recovered total protein from the urine sample of $\mathrm{P} 1$, separated the proteins on SDS-polyacrylamide gel, detected corresponding protein bands by Coomassie blue staining (Fig. 2b), excised them and analysed them by mass spectrometry (Fig. 2c). The analysis showed that the abnormal protein with the lower molecular mass was UMOD lacking a C-terminal part. With K432 being the last amino acid positively identified, the cleavage site leading to this abnormal proteolytic processing is most likely to be located between amino acid residues K432 and R449 (Fig. 2d).

The patients chosen for this study were enrolled in three different treatment protocols using either the synthetic ceramide glucosyltransferase inhibitor Zavesca (miglustat; Actelion Pharmaceuticals Ltd, Allschwil, Switzerland) or two available recombinant GLA preparations, Fabrazyme (Genzyme, Cambridge, MA, USA) and Replagal (Shire Human Genetic Therapies AB, Danderyd, Sweden). To investigate eventual effects of the treatment protocols on abnormal UMOD excretion and processing, we analysed urine samples collected before and during the individual trials (Fig. 3). Abnormal processing of UMOD clearly normalized in all patients receiving ERT with Fabrazyme (Fig. 3b) and Replagal (Fig. 3c). The effect of Zavesca treatment was not as striking (Fig. 3a).

UMOD expression in situ and its relation to the storage process

To explain the observed abnormalities in urinary UMOD excretion and processing, we studied UMOD cellular expression and its relation to the storage in different parts of nephron and collecting duct in archived kidney tissues from two untreated hemizygotes and one heterozygous patient whose urine samples were unfortunately not available for correlation. 
a

\section{b}

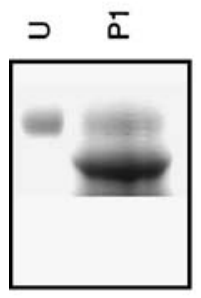

c

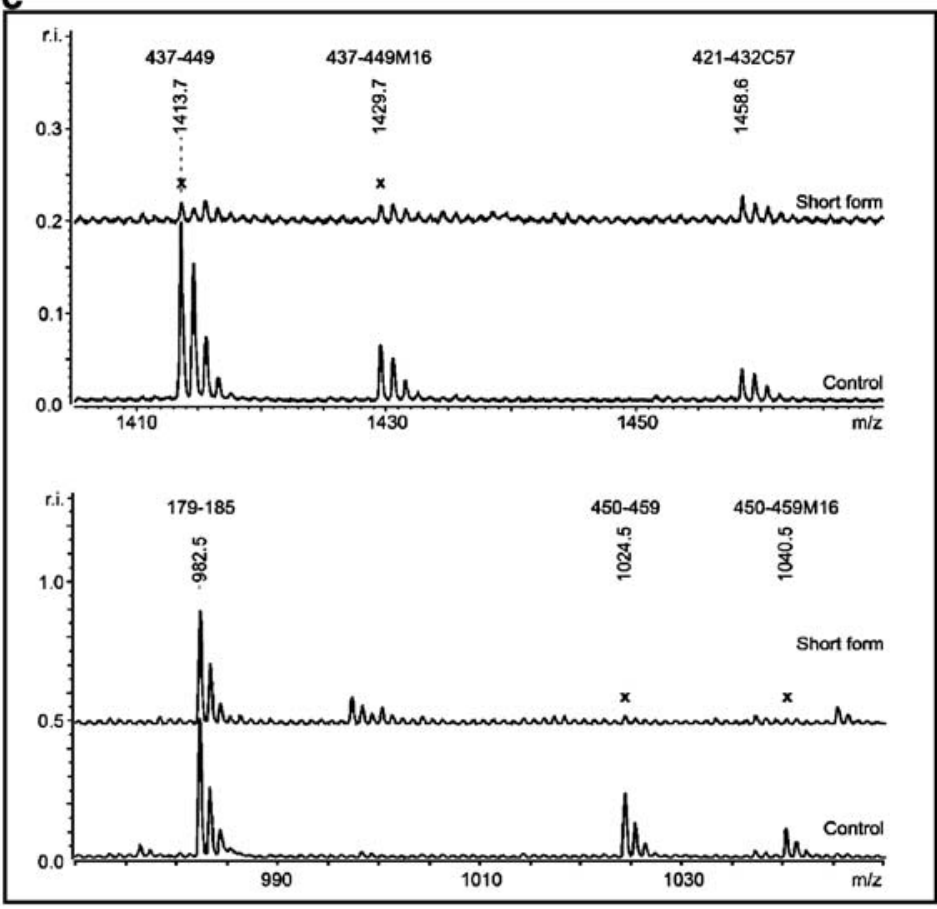

d

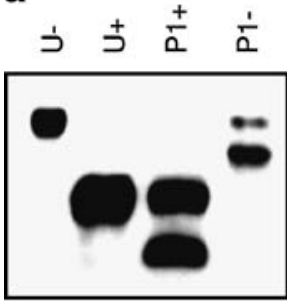

1 MGQPSLTWML MVVVASWFIT TAATDTSEAR WCSECHSNAT CTEDEAVTTC TCQEGFTGDG LTCVDLDECA 1 MGQPSLTWML MVVVASWFIT TAATDTSEAR WCSECHSNAT CTEDEAVTTC TCQEGFTGDG LTCVDLDECA

71 IPGAHNCSAN SSCVNTPGSF SCVCPEGFRL SPGLGCTDVD ECAEPGLSHC HALATCVNVV GSYLCVCPAG 71 IPGAHNCSAN SSCVNTPGSF SCVCPEGFRL SPGLGCTDVD ECAEPGLSHC HALATCVNVV GSYLCVCPAG

141 YRGDGWHCEC SPGSCGPGLD CVPEGDALVC ADPCQAHRTL DEYWRSTEYG EGYACDTDLR GWYRFVGQGG 141 YRGDGWHCEC SPGSCGPGLD CVPEGDALVC ADPCQAHRTL DEYWRSTEYG EGYACDTDLR GWYRFVGQGG

211 ARMAETCVPV LRCNTAAPMW LNGTHPSSDE GIVSRKACAH WSGHCCLWDA SVQVKACAGG YYVYNLTAPP

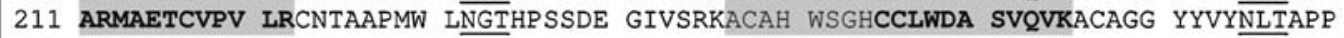

281 ECHLAYCTDP SSVEGTCEEC SIDEDCKSNN GRWHCQCKQD FNITDISLLE HRLECGANDM KVSLGKCQLK 281 ECHLAYCTDP SSVEGTCEEC SIDEDCKSNN GRWHCQCKQD FNITDISLLE HRLECGANDM KVSLGKCQLK

351 SLGEDKVFMY LSDSRCSGFN DRDNRDWVSV VTPARDGPCG TVLTRNETHA TYSNTLYLAD EIIIRDLNIK 351 SLGEDKVFMY LSDSRCSGFN DRDNRDWVSV VTPARDGPCG TVLTRNETHA TYSNTLYLAD EIIIRDLNIK

421 INFACSYPLD MKVSLKTALQ PMVSALNIRV GGTGMFTVRM ALFQTPSYTQ PYQGSSVTLS TEAFLYVGTM

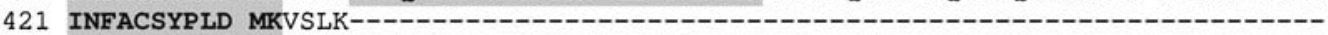

491 LDGGDLSRFA LLMTNCYATP SSNATDPLKY FIIQDRCPHT RDSTIQVVEN GESSQGRFSV QMFRFAGNYD 491

561 LVYLHCEVYL CDTMNEKCKP TCSGTRFRSG SVIDQSRVLN LGPITRKGVQ ATVSRAFSSL GLLKVWLPLL

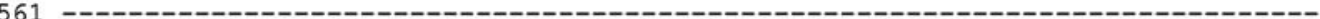

631 LSATLTLTFO

631 ----------

Fig. 2 Characterization of abnormal UMOD processing. (a) Qualitative analysis (western blot) of UMOD isolated from healthy male urine before ( $\left.\mathrm{U}^{-}\right)$and $\left(\mathrm{U}_{+}\right)$after deglycosylation treatment with $N$-glycanase. P1 - indicates urine from patient P1 before and $\mathrm{P} 1+$ after deglycosylation treatment with $\mathrm{N}$-glycanase. (b) Qualitative analysis (Coomassie blue-stained SDSPAGE gel) of total protein extract obtained from $500 \mu \mathrm{l}$ of urine from patient P1 on Amicon YM-50. U: UMOD standard isolated from control urine. (c) Peptide mass fingerprinting of UMOD standard (control) and isolated protein of interest confirms that 'short form' is UMOD protein lacking the $\mathrm{N}$-terminal part following 432K residue. M16 indicates oxidized methionine. C57 indicates cysteine iodoacetamide. (d) Sequence alignment of the control urinary UMOD (upper sequence) and the patient 'short form' (lower sequence) shows with grey highlight peptides detected by peptide mass fingerprinting and in bold type peptides that were confirmed by peptide microsequencing. Theoretical N-glycosylation sites of UMOD are underlined 
$U M O D$ in situ expression in control kidney samples was restricted to the epithelial cells of the TALH and the DCT. In the latter, the expression was lower and variable. UMOD was maximally expressed in the apical pole with less intracellular positivity. Exceptionally there was also staining at the basolateral pole. Rarely there was slight positivity in some cells in collecting tubules.

Distribution of the storage in Fabry disease kidneys. In the cortex, storage was absent in both the proximal and the distal tubules. It was present only in glomeruli and in vessels (endothelia and smooth-muscle cells). The tubular storage dominated in the medullary parts of the nephron (both descending and ascending limbs of the loop of Henle) and in the system of collecting tubules, decreasing from the outer medulla to the papilla. Corresponding tubular segments (parts) differed considerably in the degree of storage. In the collecting tubules, the storage was more pronounced in the intercalated cells. There were also signs of tubular regeneration (binucleate cells, cells with flat cytoplasm) and degeneration (cell shrinkage and nuclear pycnosis) and focal fibrosis in the medulla, mainly in its outer part. The storage pattern in the heterozygous Fabry kidney was the same as described in both hemizygotes.
UMOD in situ expression in Fabry disease kidneys. UMOD signal was present with similar intensity as in controls in the non-storing TALH and in the DCT. The number of tubules strongly positive for UMOD in the cortex was comparable to that in control kidneys (Fig. 4a, b) but was decreased in the outer medulla (Fig. 4c, d). In many cross-sections of TALH, there were strongly UMOD-positive epithelia free of recognizable storage mixed with cells in advanced stage of storage and decreased or absent UMOD staining (Fig. 4e). In general, the degree of UMOD expression was inversely proportional to the degree of lysosomal storage (Fig. 4f). In cells with lesser degrees of storage, UMOD apical presentation was preserved but often combined with staining at the basolateral pole (Fig. 4g). In some collecting tubules there was UMOD signal at the cell membrane as well as intracellularly, suggesting ectopic expression (Fig. 4h). This finding was more frequent than in controls but was not entirely bound to advanced lysosomal storage. Several UMOD-positive luminal casts were also observed. UMOD staining in the heterozygous Fabry kidney did not differ from that in the samples from the hemizygous patients.

In parallel the marker of the apical membrane, MUC1, was present throughout the whole nephron

a

\begin{tabular}{|c|c|c|c|c|c|c|c|c|c|c|c|c|c|c|c|c|c|c|c|c|}
\hline \multirow{2}{*}{$\mathrm{U}$} & \multicolumn{3}{|c|}{ P1 } & \multicolumn{4}{|c|}{ P11 } & \multicolumn{4}{|c|}{ P2 } & \multicolumn{3}{|c|}{ P3 } & \multicolumn{4}{|c|}{ P14 } & \multicolumn{2}{|c|}{ P15 } \\
\hline & A & B & C & A & B & C & D & A & B & C & D & A & B & D & A & B & C & D & A & D \\
\hline
\end{tabular}

b

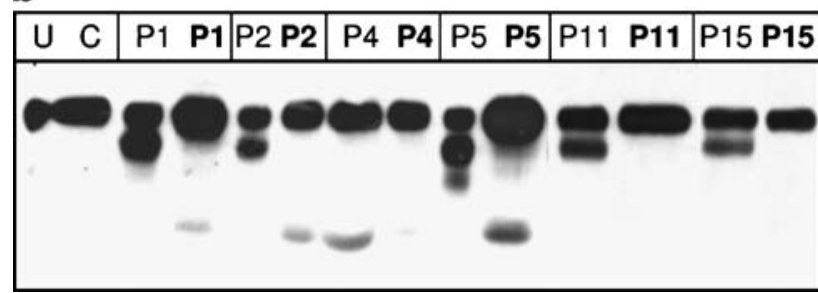

C

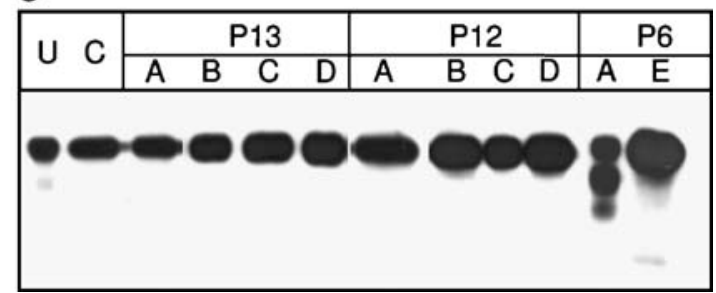

Fig. 3 Qualitative analysis (western blot) of urinary UMOD in patients with Fabry disease on various therapy protocols. (a) Zavesca protocol. Urine samples were collected (A) before treatment, (B) at 6 months, (C) at the end of treatment (12 months) and (D) 1 month after termination of the treatment. (b) Fabrazyme protocol. Samples taken before and during the treatment are in plain and bold characters, respectively. (c) Replagal protocol. Urine samples were collected (A) before treatment, (B) at 1 month, (E) at 2 months, (C) at 3 months and (D) 1 month after termination of the treatment. U: uromodulin standard isolated from control urine, C: control urine, P1-P15: patient designation as provided in Table 1 . The low molecular weight bands seen at the bottom of images most probably represent albumin, reflecting disease-related proteinuria 

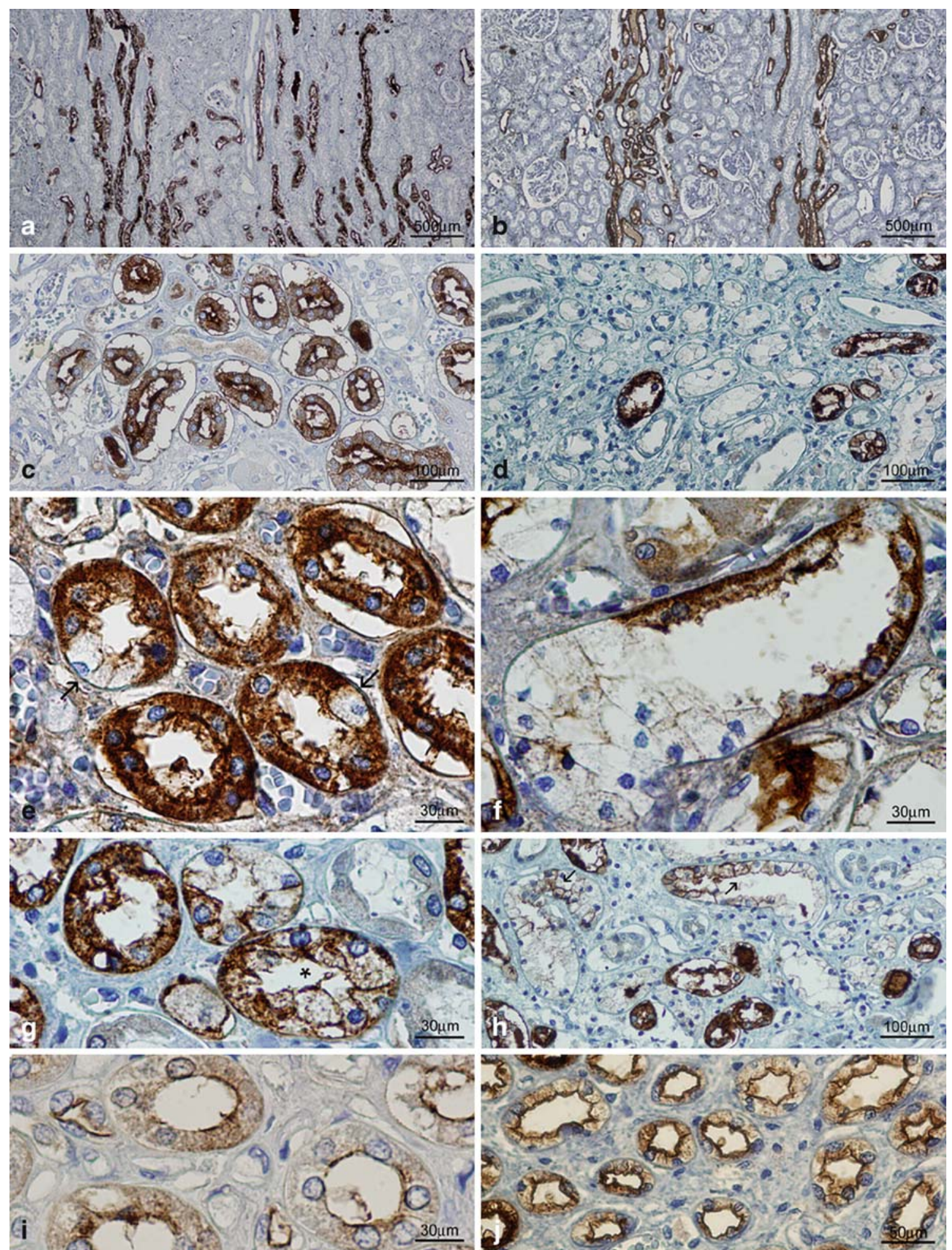

Fig. 4 Immunohistochemical analysis of UMOD and MUC1 in kidney biopsies. Survey of the cortical medullary rays shows strong and comparable UMOD expression (a) in control and (b) in Fabry disease kidney where cortical TALH is without prominent lysosomal storage. Differences in UMOD expression were present in the outer medulla. (c) In the control the staining in TALH is uniform whereas (d) in Fabry disease kidney the absence of UMOD staining is seen in many cross-sectioned TALH displaying storage. Details of the outer medulla in Fabry

disease kidney show (e) absence of UMOD expression in individual storage TALH cells (arrows) and (f) UMOD expression in TALH inversely proportional to the degree of storage. (g) Storage TALH epithelium with persistent decreased apical UMOD expression (asterisk). (h) Collecting tubules (arrows) with distinct apical and basolateral UMOD positivity. MUC1 expression is identical in both (i) control and (j) despite the storage also in Fabry disease kidney 
with the exception of proximal convoluted tubules, and in the collecting tubules as in controls. There was no significant reduction of MUC1 expression due to storage (Fig. 4i, j).

\section{Discussion}

We present here the results of a pilot study investigating UMOD urinary excretion, processing and expression in patients with Fabry disease at different clinical stages of the disease and during treatment with ERT or SRT. This work has been undertaken with the aim of extending knowledge of the range of UMOD changes in various genetic diseases with severe renal involvement, starting with the model of Fabry disease. In about half of the untreated hemizygous male patients as well as in 7 out of 9 heterozygous carriers (data not shown), we found significant quantitative and qualitative changes in urinary UMOD excretion, which indicate a gradual decrease in urinary UMOD excretion accompanied in some cases by aberrant proteolytic UMOD processing. Variability in UMOD excretion seemed in most patients to reflect phenotypic severity (with the exception of P12 and P13) as it correlates with the reported Mainz severity score index. This speculation is further supported by the finding that UMOD urinary excretion patterns normalized in all patients enrolled in ERT and, to a lesser extent, in patients on SRT. Reversibility of abnormal UMOD excretion profile after ERT and SRT represents a key observation as it links the changes of UMOD biology to the storage process in TALH and the DCT.

Existing studies addressing the nephron storage distribution in Fabry disease differ surprisingly with regard to definition of the individual affected segments. Storage in the proximal part has been reported only rarely (Alroy et al 2002; Farge et al 1985; McNary and Lowenstein 1965; Wornell et al 2006). Storage in collecting tubules was found to be present in only two reports (Alroy et al 2002; Burkholder et al 1980), while others described storage in the distal tubules (Burkholder et al 1980; Dempsey et al 1965; Faraggiana et al 1981; Farge et al 1985; Gubler et al 1978; McNary and Lowenstein 1965; Pabico et al 1973; Tondeur and Resibois 1969; Wornell et al 2006). The distal tubule and the Henle loop are thus considered to be affected most prominently in Fabry disease (Okuda 2000). The storage pattern in heterozygotes did not differ substantially from that in hemizygous male patients (Farge et al 1985; Gubler et al 1978).

We observed storage in the loop of Henle and in the collecting ducts with notable degrees of variability between individual tubules. In particular, storage in the TALH had a mosaic character. Similar variability in storage has been described before (Gubler et al 1978). As in previous studies on UMOD expression in control kidney, we observed prominent expression of UMOD in the TALH and less so in the DCT in normal kidneys (Hoyer and Seiler 1979; Peach et al 1988; Schenk et al 1971; Sikri et al 1981). Thus, both processes, lysosomal storage and UMOD expression, meet in the TALH.

Normal, fully processed UMOD detected in the patient urine samples is most probably produced by cells not affected by storage process and showing UMOD staining like that in controls. Decrease in UMOD excretion might be attributed to its attenuated expression as shown by the UMOD staining pattern, which is inversely proportional to the degree of storage in patient kidney. Attenuated UMOD expression, however, cannot be attributed to generally compromised proteosynthesis because another marker of apical membrane, MUC1, showed normal expression pattern in unaffected as well as storing cells. Attenuated UMOD expression is thus probably linked directly to the lysosomal storage process. Similar decrease in UMOD transcription and expression was found recently in mice with renal-specific inactivation of HNF1 $\beta$ (Gresh et al 2004), Brn1 ${ }^{-1-}$ mice (Nakai et al 2003), an ischaemia-reperfusion model of ARF in rat (Yoshida et al 2002), in some patients with UAKD (Hodanova et al 2005; Vylet'al et al 2006), and in kidney damage (Chakraborty et al 2004).

The other interesting observation of our study represents aberrant proteolytic processing of UMOD. Our results do not define the site and mechanism of this process. It may be intracellular as a result of storage-related proteosome and/or specific protease activation. It may also occur on the cell membrane by a process of abnormal ectodomain shedding. This process may be activated by glomerulopathy-related changes in tubular fluid composition (proteinuria, osmolarity, $\mathrm{pH}$ ), which may alter the tertiary structure of UMOD and make it susceptible to aberrant cleavage either by UMOD-specific or other proteases present in urine. This latter explanation seems more likely as distinct UMOD staining may be seen on the apical membrane of storing as well as non-storing epithelial 
cells (Fig. 4). The alternative processing can also reflect alternative proteolytic cleavage in desquamated tubular storage epithelia responsible for the massive urinary lipid excretion.

In conclusion, storage processes in Fabry disease trigger mechanisms that lead to reduced expression, alternative proteolytic processing and decreased urinary excretion of UMOD. Lack of UMOD function(s) has been shown to be associated with impairment of tubular function, particularly of the urine-concentrating process, accounting for water depletion in UAKD (Bleyer et al 2003; Scolari et al 2004; Vylet'al et al 2006). It is therefore reasonable to speculate that the observed changes in UMOD expression may contribute to altered tubular functions in Fabry disease as well. Association of UMOD changes with the degree of the storage process and its reversibility by ERT and partly also by SRT suggests that UMOD excretion monitoring may be a useful marker, particularly of response to treatment. We suggest that UMOD might be an additional marker of therapeutic in situ effect on $\mathrm{Gb}_{3}$, the excretion of which may be affected by cleavage of lipid released from the desquamated storage epithelia by the applied recombinant enzyme (Christensen et al 2007). Extended study and especially detailed comparative studies of UMOD expression in kidney specimens obtained before and during individual types of available therapies are therefore of great interest.

Acknowledgements We thank Dr Venkat Raman for comments and critical reading of the manuscript. This work was supported by grant MSM0021620806 from the Ministry of Education of the Czech Republic and partly by grant number 257750 from the Grant Agency of Charles University in Prague (GAUK).

\section{References}

Alroy J, Sabnis S, Kopp JB (2002) Renal pathology in Fabry disease. J Am Soc Nephrol 13(Supplement 2): S134-138.

Bernascone I, Vavassori S, Di Pentima A, et al (2006) Defective intracellular trafficking of uromodulin mutant isoforms. Traffic 7: 1567-1579.

Bleyer AJ, Trachtman H, Sandhu J, Gorry MC, Hart TC (2003) Renal manifestations of a mutation in the uromodulin (Tamm Horsfall protein) gene. Am J Kidney Dis 42: E20-26.

Bleyer AJ, Hart TC, Shihabi Z, Robins V, Hoyer JR (2004) Mutations in the uromodulin gene decrease urinary excretion of Tamm-Horsfall protein. Kidney Int 66: 974-977.

Breunig F, Wanner C (2003) Enzyme replacement therapy for Fabry disease: proving the clinical benefit. Nephrol Dial Transplant 18: 7-9.
Burkholder PM, Updike SJ, Ware RA, Reese OG (1980) Clinicopathologic, enzymatic, and genetic features in a case of Fabry's disease. Arch Pathol Lab Med 104: 17-25.

Cavallone D, Malagolini N, Serafini-Cessi F (2001) Mechanism of release of urinary Tamm-Horsfall glycoprotein from the kidney GPI-anchored counterpart. Biochem Biophys Res Commun 280: 110-114.

Chakraborty J, Below AA, Solaiman D (2004) Tamm-Horsfall protein in patients with kidney damage and diabetes. Urol Res 32: 79-83.

Christensen EI, Zhou Q, Sorensen SS, et al (2007) Distribution of alpha-galactosidase A in normal human kidney and renal accumulation and distribution of recombinant alpha-galactosidase A in Fabry mice. J Am Soc Nephrol 18: 698-706.

Clapp WL, Croker BP (1997) Adult kidney. In: Sternberg SS, ed. Histology for Pathologists, 2nd edn. Philadelphia: LippincottRaven, 799-834.

Cohen AH (1981) Morphology of renal tubular hyaline casts. Lab Invest 44: 280-287.

Dahan K, Devuyst O, Smaers M, et al (2003) A cluster of mutations in the UMOD gene causes familial juvenile hyperuricemic nephropathy with abnormal expression of uromodulin. J Am Soc Nephrol 14: 2883-2893.

De Schoenmakere G, Chauveau D, Grunfeld JP (2003) Enzyme replacement therapy in Anderson-Fabry's disease: beneficial clinical effect on vital organ function. Nephrol Dial Transplant 18: 33-35.

del Toro N, Milan JA, Palma A (2004) Enzyme replacement in the treatment of Fabry's disease. Is there a point-ofno-return? Nephrol Dial Transplant 19: 1018.

Dempsey H, Hartley MW, Carroll J, Balint J, Miller RE, Frommeyer WB Jr. (1965) Fabry's disease (angiokeratoma corporis diffusum): case report on a rare disease. Ann Intern Med 63: 1059-1068.

Desnick RJ, Astrin KH, Bishop DF (1989) Fabry disease: molecular genetics of the inherited nephropathy. $A d v$ Nephrol Necker Hosp 18: 113-127.

Dobrovolny R, Dvorakova L, Ledvinova J, et al (2005) Relationship between $\mathrm{X}$-inactivation and clinical involvement in Fabry heterozygotes. Eleven novel mutations in the alphagalactosidase A gene in the Czech and Slovak population. $J$ Mol Med 83: 647-654.

Fairley JK, Owen JE, Birch DF (1983) Protein composition of urinary casts from healthy subjects and patients with glomerulonephritis. Br Med J (Clin Res Ed) 287: 1838-1840.

Faraggiana T, Churg J, Grishman E, et al (1981) Light- and electron-microscopic histochemistry of Fabry's disease. $\mathrm{Am}$ J Pathol 103: 247-262.

Farge D, Nadler S, Wolfe LS, Barre P, Jothy S (1985) Diagnostic value of kidney biopsy in heterozygous Fabry's disease. Arch Pathol Lab Med 109: 85-88.

Fukuoka S, Kobayashi K (2001) Analysis of the C-terminal structure of urinary Tamm-Horsfall protein reveals that the release of the glycosyl phosphatidylinositol-anchored counterpart from the kidney occurs by phenylalaninespecific proteolysis. Biochem Biophys Res Commun 289: 1044-1048.

Glass RB, Astrin KH, Norton KI, et al (2004) Fabry disease: renal sonographic and magnetic resonance imaging findings in affected males and carrier females with the classic and cardiac variant phenotypes. J Comput Assist Tomogr 28: $158-168$. 
Gresh L, Fischer E, Reimann A, et al (2004) A transcriptional network in polycystic kidney disease. Embo J 23: 1657-1668.

Gubler MC, Lenoir G, Grunfeld JP, Ulmann A, Droz D, Habib R (1978) Early renal changes in hemizygous and heterozygous patients with Fabry's disease. Kidney Int 13: 223-235.

Hart TC, Gorry MC, Hart PS, et al (2002) Mutations of the UMOD gene are responsible for medullary cystic kidney disease 2 and familial juvenile hyperuricaemic nephropathy. J Med Genet 39: 882-892.

Hodanova K, Majewski J, Kublova M, et al (2005) Mapping of a new candidate locus for uromodulin-associated kidney disease (UAKD) to chromosome 1q41. Kidney Int $\mathbf{6 8}$ : $1472-1482$.

Hoyer JR, Seiler MW (1979) Pathophysiology of Tamm-Horsfall protein. Kidney Int 16: 279-289.

Kreft B, Jabs WJ, Laskay T, et al (2002) Polarized expression of Tamm-Horsfall protein by renal tubular epithelial cells activates human granulocytes. Infect Immun 70: 2650-2656.

Kumar S, Muchmore A (1990) Tamm-Horsfall proteinuromodulin (1950-1990). Kidney Int 37: 1395-1401.

Masson C, Cisse I, Simon V, Insalaco P, Audran M (2004) Fabry disease: a review. Joint Bone Spine 71: 381-383.

McNary WF, Lowenstein LM (1965) A morphological study of the renal lesion in angiokeratoma corporis diffusum universale (Fabry's disease). J Urol 93: 641-648.

Morel-Maroger L, Ganter P, Ardaillou R, Cathelineau G, Richet G (1966) [Histochemical study of a lipid thesaurismosis with renal, cutaneous and neurologic involvement. Its relation to Fabry's angiokeratosis and familial renal cytodystrophy]. Bull Mem Soc Med Hop Paris 117: $49-57$.

Nakai S, Sugitani Y, Sato H, et al (2003) Crucial roles of Brn1 in distal tubule formation and function in mouse kidney. Development 130: 4751-4759.

Okuda S (2000) Renal involvement in Fabry's disease. Intern Med 39: 601-602.

Pabico RC, Atancio BC, McKenna BA, Pamukcoglu T, Yodaiken R (1973) Renal pathologic lesions and functional alterations in a man with Fabry's disease. Am J Med 55: 415-425.

Parchoux B, Guibaud P, Maire I, et al (1978) [Fabry's disease. Initial nephrogenic diabetes insipidus in children]. Pediatrie 33: $757-765$.
Peach RJ, Day WA, Ellingsen PJ, McGiven AR (1988) Ultrastructural localization of Tamm-Horsfall protein in human kidney using immunogold electron microscopy. Histochem J 20: 156-164.

Rampoldi L, Caridi G, Santon D, et al (2003) Allelism of MCKD, FJHN and GCKD caused by impairment of uromodulin export dynamics. Hum Mol Genet 12: 3369-3384.

Rindler MJ, Naik SS, Li N, Hoops TC, Peraldi MN (1990) Uromodulin (Tamm-Horsfall glycoprotein/uromucoid) is a phosphatidylinositol-linked membrane protein. J Biol Chem 265: 20784-20789.

Scolari F, Caridi G, Rampoldi L, et al (2004) Uromodulin storage diseases: clinical aspects and mechanisms. Am J Kidney Dis 44: 987-999.

Serafini-Cessi F, Malagolini N, Hoops TC, Rindler MJ (1993) Biosynthesis and oligosaccharide processing of human Tamm-Horsfall glycoprotein permanently expressed in HeLa cells. Biochem Biophys Res Commun 194: 784-790.

Schenk EA, Schwartz RH, Lewis RA (1971) Tamm-Horsfall mucoprotein. I. Localization in the kidney. Lab Invest 25 : 92-95.

Sikri KL, Foster CL, MacHugh N, Marshall RD (1981) Localization of Tamm-Horsfall glycoprotein in the human kidney using immuno-fluorescence and immuno-electron microscopical techniques. J Anat 132: 597-605.

Tondeur M, Resibois A (1969) Fabry's disease in children. An electron microscopic study. Virchows Arch B Cell Pathol 2: 239-254.

Vylet'al P, Kublova M, Kalbacova M, et al (2006) Alterations of uromodulin biology: a common denominator of the genetically heterogeneous FJHN/MCKD syndrome. Kidney Int 70: $1155-1169$.

Wenk RE, Bhagavan BS, Rudert J (1981) Tamm-Horsfall uromucoprotein and the pathogenesis of casts, reflux nephropathy, and nephritides. Pathobiol Annu 11: 229-257.

Wornell P, Dyack S, Crocker J, Yu W, Acott P (2006) Fabry disease and nephrogenic diabetes insipidus. Pediatr Nephrol 21: 1185-1188.

Yoshida T, Kurella M, Beato F, et al (2002) Monitoring changes in gene expression in renal ischemia-reperfusion in the rat. Kidney Int 61: 1646-1654. 